Okajimas Folia Anat. Jpn., 86(1): 7-16, May, 2009

\title{
Lamination of the Masticatory Muscles in the Phascolarctos cinereus (Koala) According to Their Innervations
}

\author{
By \\ Koh NAKAJIMA ${ }^{1}$ and Grant TOWNSEND ${ }^{2}$ \\ ${ }^{1}$ Department of Oral Anatomy and Developmental Biology, Showa University, School of Dentistry \\ Hatanodai 1-5-8, Shinagawa-ku, Tokyo, Japan, 142-8555 \\ ${ }^{2}$ Dental School, The University of Adelaide, Adelaide, South Australia, Australia 5005
}

-Received for Publication, November 18, $2008-$

\begin{abstract}
Key Words: Macroscopic Anatomy, Masticatory muscles, Mandibular nerve, Koala, Marsupialia
Summary: The masticatory muscles are usually classified into four groups: masseter, temporalis, lateral pterygoid and medial pterygoid. The communicating muscle bundle between the temporalis and masseter called the zygomaticomandibular muscle exists. The laminations within these muscles are commonly separated by aponeuroses. Nerves control the action of muscles, so improved understanding about innervation patterns in the masticatory muscles is important in the consideration of muscle function. In this study, we focus on the relationships between the nerves supply and the lamination of masticatory muscles in Phascolarctos cinereus (Koala).

The masseter muscle consists of superficial and deep muscle layers. The superficial muscle layer of the masseter muscle is divided into rostro-lateral and caudo-internal nerve layers. The deep muscle layer of the masseter muscle is divided into rostral, rostro-lateral, medial and caudo-internal nerve layers. The nerves that innervate the zygomaticomandibular muscle are distributed to the lateral area of the coronoid process. The temporalis muscle was divided into internal layer of the coronoid process, a lateral layer of the coronoid process and a posterior layer by the nerve distribution pattern. The medial pterygoid muscle divided into rostro-internal, medial and caudo-lateral nerve layers.
\end{abstract}

\section{Introduction}

The masticatory muscles are usually classified into four groups: masseter, temporalis, lateral pterygoid and medial pterygoid. The muscle bundle of the temporalis muscle communicates with those of the masseter and lateral pterygoid muscles. In particular, the communicating muscle bundle between temporalis and masseter is called the zygomaticomandibular muscle (Toldo, 1907; Schumacher, 1974; Sicher, 1952). Even if this muscle acts independently, its action is still essentially for mastication. Indeed these actions influence the other masticatory muscles. Therefore, we believe that the masticatory muscles act as a co-operative single muscular unit. In studies of lamination within these muscles, separations by aponeuroses have often been described (Sawada, 1976; Yoshikawa, 1969; Yosikawa and Suzuki, 1962a, b; Yosikawa et al., 1961, 1962a, b). However, the positions of the aponeuroses do not necessarily conform to muscle action. In fact, nerves distributed into muscle bundles from other muscle layers often penetrate tendons or apo- neuroses (Koppe et al., 1988; Schumacher et al., 1974; Lau et al., 1974; Widmer, 1997). Some researchers have noted specific nerve distributions within these muscles (Akita et al., 2000; Nakajima, 2001; Nakajima et al., 1998, 2000; Shimokawa et al., 1988, 1999; Tomo, 1990; Tomo et al., 1993; Watanabe, 1997). Nerves control the action of muscles, so improved understanding about innervation patterns in the masticatory muscles is important in the consideration of muscle function.

$P$. cinereus's possess rostro-caudally elongated heads as other herbivorous animal. The zygomatic arch, which is comprised of the zygomatic process of squamosal bone $(\mathrm{Z})$ and the jugal bone ( $\mathrm{J}$ ), is elongated rostro-caudally and broad supra-inferiorly (Figs. 1-2). The mandible is also elongated rostro-caudally, with well-developed ramus and well-developed masseteric fossa (MF) (Fig. 3). The $P$. cinereus is an anisognathous animal with a dental occlusion that provides wide lateral mandibular movements. The masseter muscle arises from the zygomatic arch and descending process of the jugal bone (DP). It inserts into a region that extends from the angular process

Corresponding author: Koh Nakajima, Department of Oral Anatomy and Developmental Biology, Showa University, School of Dentistry, Hatanodai 1-5-8, Shinagawa-ku, Tokyo, Japan. E-mail: kohnaka@dent.showa-u.ac.jp 


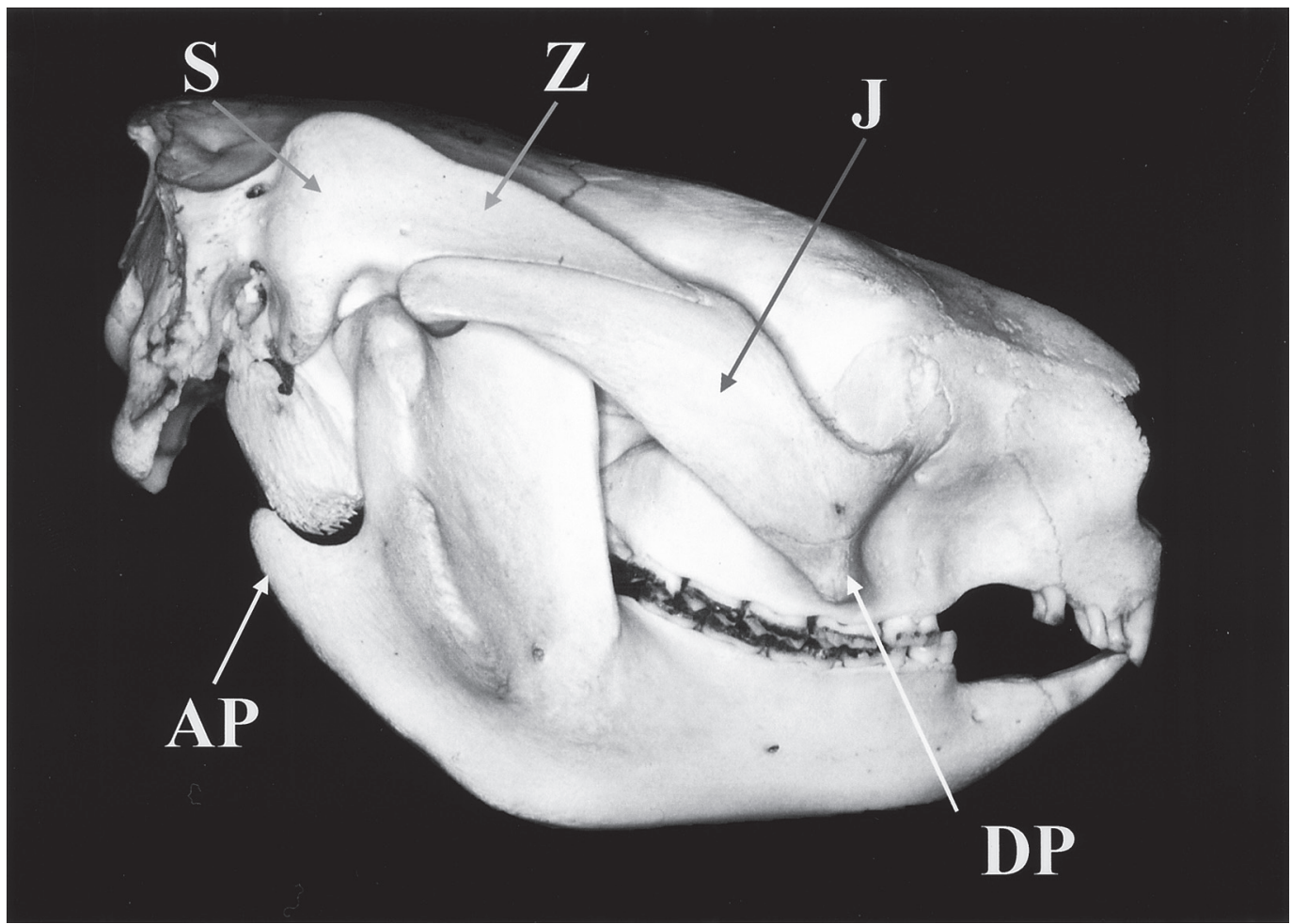

Fig. 1. P. cinereus's skull observed from lateral. AP, Angular process; DP, Descending Process of jugal bone; J, Jugal arch; S, Squamosal bone; Z, Zygomatic process of squamosal bone.

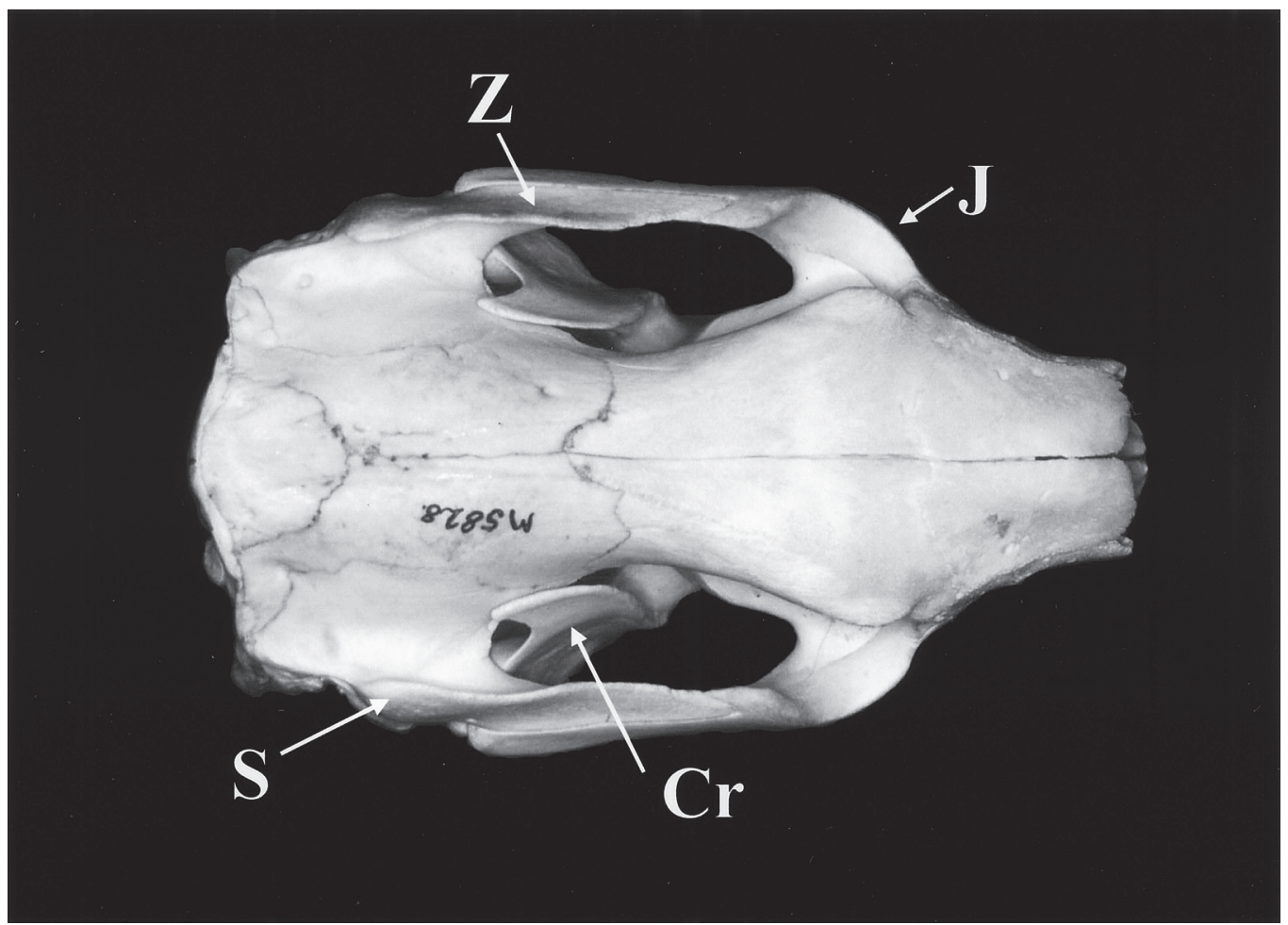

Fig. 2. P. cinereus's skull observed from above. Cr, Coronoid process; J, Jugal arch; S, Squamosal bone; Z, Zygomatic process of squamosal bone. 


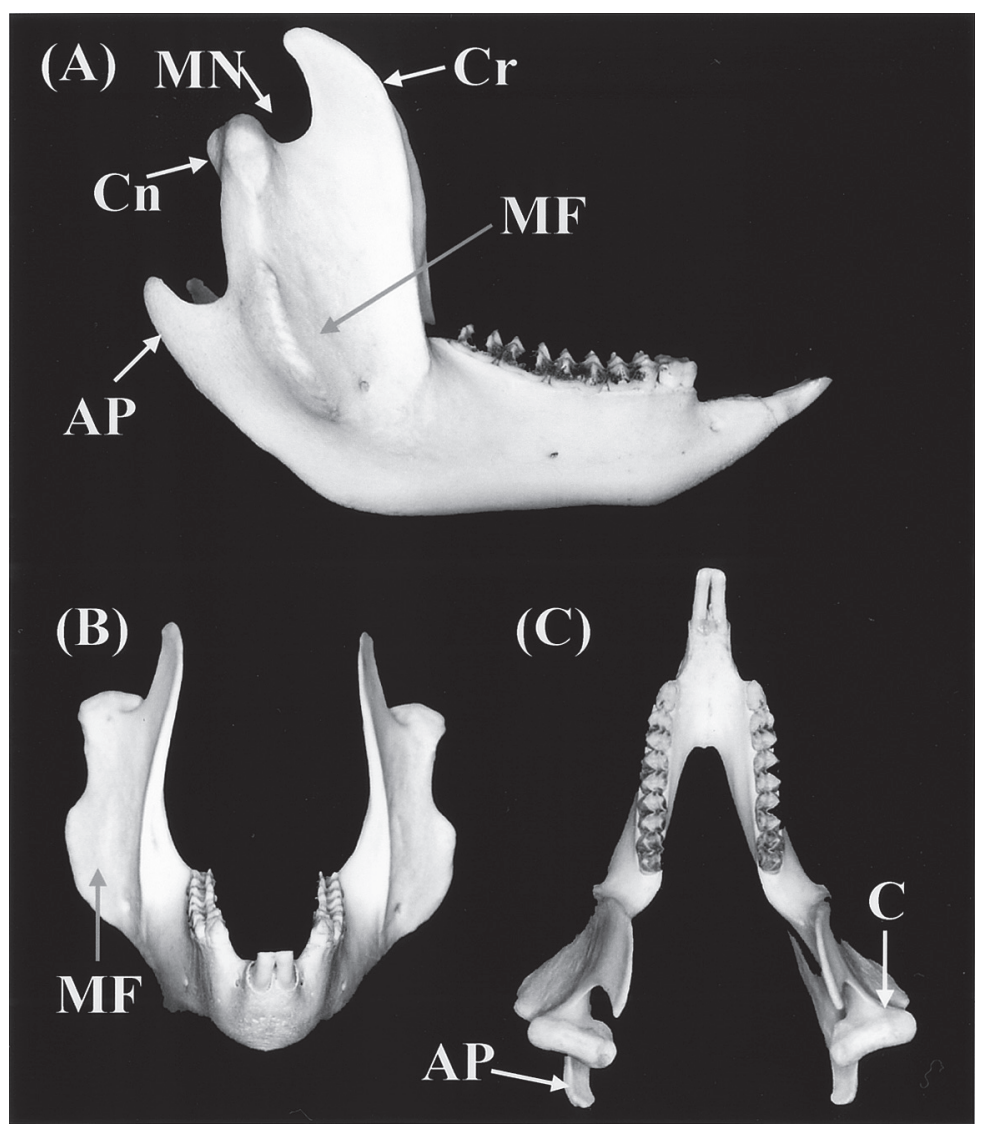

Fig. 3. P. cinereus's mandible (A: lateral view, B: frontal view, C: superior view). AP, Angular process; $\mathrm{Cn}$, Condyle; Cr, Coronoid process; MF, Masseteric fossa; MN, Mandibular notch.

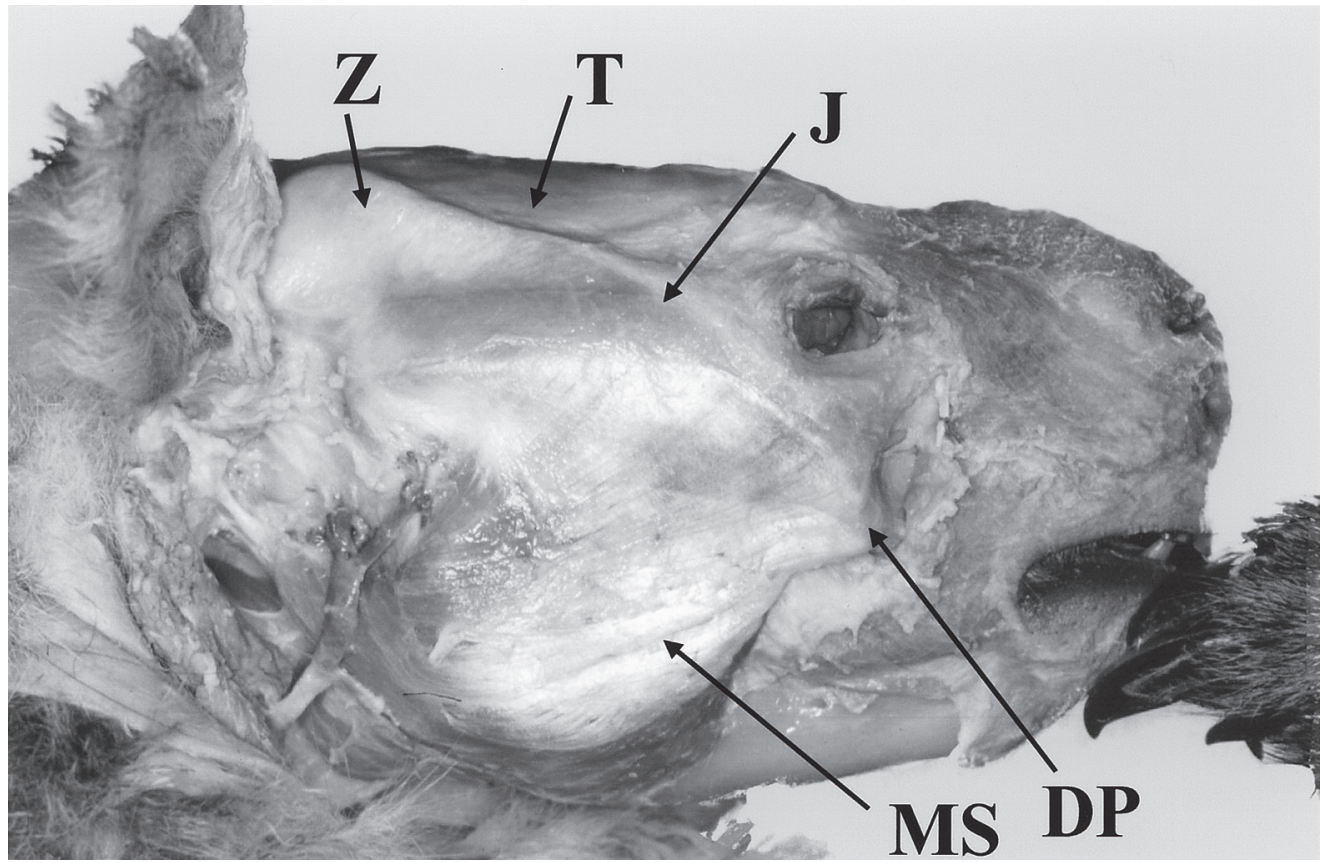

Fig. 4. Masseter of the P. cinereus (lateral view). DP, Descending Process of jugal bone; J, Jugal arch; MS, Masseter superficial layer; T, Temporalis muscle; Z, Zygomatic process of squamosal bone. 


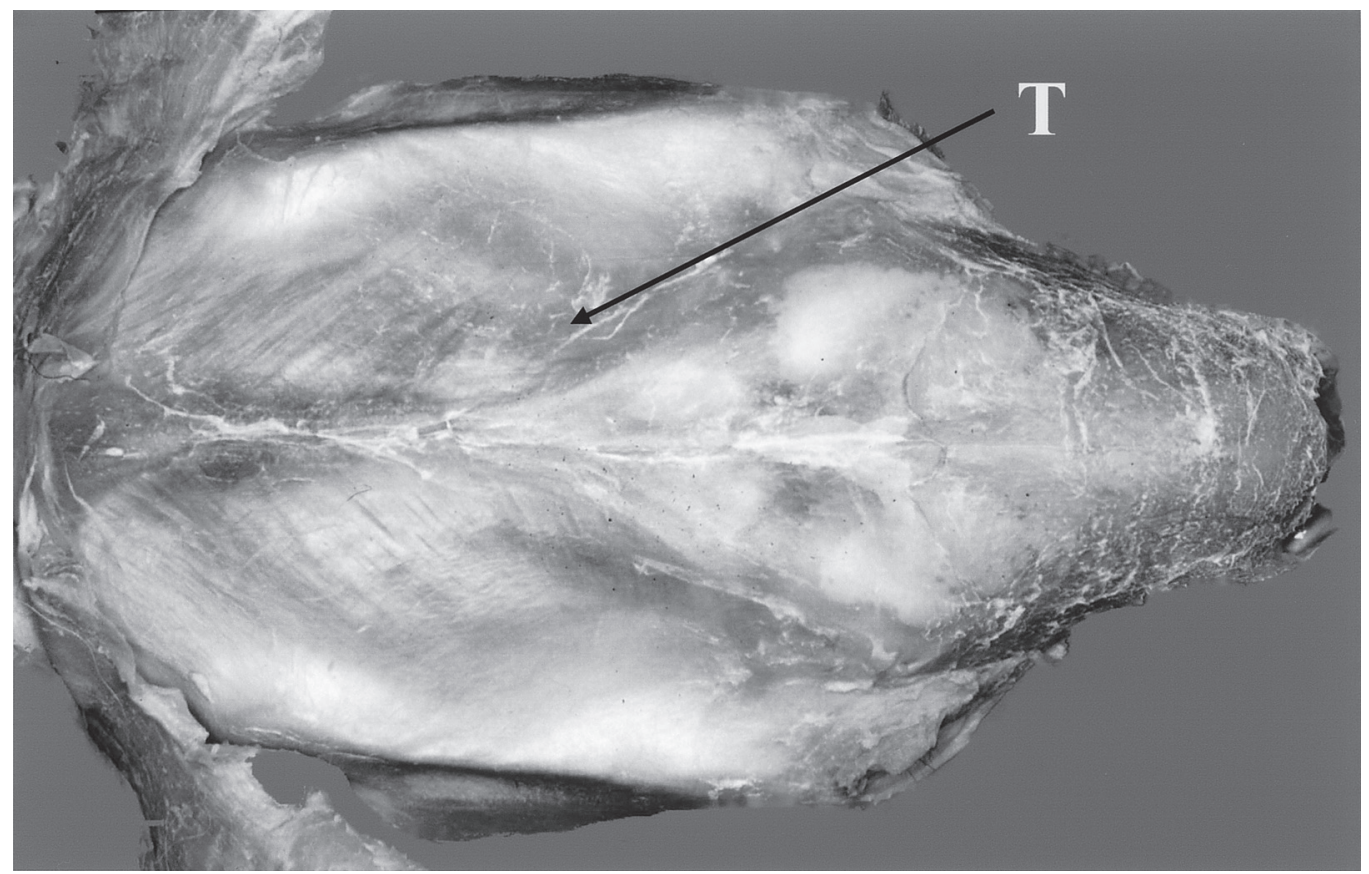

Fig. 5. Temporalis muscle of the P. cinereus (upper view). T, Temporalis muscle.

(AP) to the oblique masseteric crest of the mandible and its inferior border (Figs. 1, 3, 4). The temporalis muscle (T) originates from the sagittal crest, the temporal fossa and the infratemporal fossa and inserts into the coronoid process $(\mathrm{Cr})$. It has a typical herbivorous animal shape with its origin enlarged caudally (Fig. 5). The zygomaticomandibular muscle is located between the temporal and masseter muscles. The $P$. cinereus has a large masseter. Davison et al. (1990) reported that the masseter constituted $48.1 \%$ of the total weight of the masticatory muscles. In this paper, we focus on the relationships between the nerve supply, and the lamination of masticatory muscles in the P. cinereus.

\section{Material and Methods}

Four half heads of two $P$. cinereuse were examined in this study. The specimens were provided by the South Australian Museum. These specimens were kept in 70\% alcohol after being fixed in $10 \%$ formalin. The method of dissection was as follows. After the skin had been removed, all of the masticatory muscles were removed carefully from the cranium. The nerves supplying the masticatory muscles were identified prior to dissection. Each lamina of the muscle was divided according to its associated aponeurosis. Threads of cotton were then used to identify the continuity of every nerve that penetrated an aponeurosis. The distribution of the nerves in each removed lamina of a muscle was then determined under the stereoscopic microscope. The findings from the dissection of each lamina were collated by referring to the corresponding threads. We use the word layer for muscle layer and nerve layer, in this paper.

The mean of muscle layer is a layer that divided by aponeurosis observed in the muscle. The mean of nerve layer is a layer that divided by nerve distribution pattern observed in the muscle.

\section{Results}

\section{Mandibular nerve}

The mandibular nerve to the masticatory muscles had two main branches: the medial pterygoid nerve and the nerve to the other masticatory muscles. The latter nerve branched into the buccal nerve and three other nerves the anterior, medial and posterior deep temporal nerves. The medial and posterior deep temporal nerves formed common trunks and divided near to the temporalis muscle. The nerves that were distributed to the zygomaticomandibular muscle and masseter branched off the posterior deep temporal nerve at the mandibular notch. The lateral pterygoid nerve branched off the anterior deep temporal nerve, the common trunk of the anterior deep temporal nerve and the buccal nerve. The branching pattern of the mandibular nerve is shown in Fig. 6.

\section{Medial pterygoid nerve}

The medial pterygoid nerve divided into three branch- 


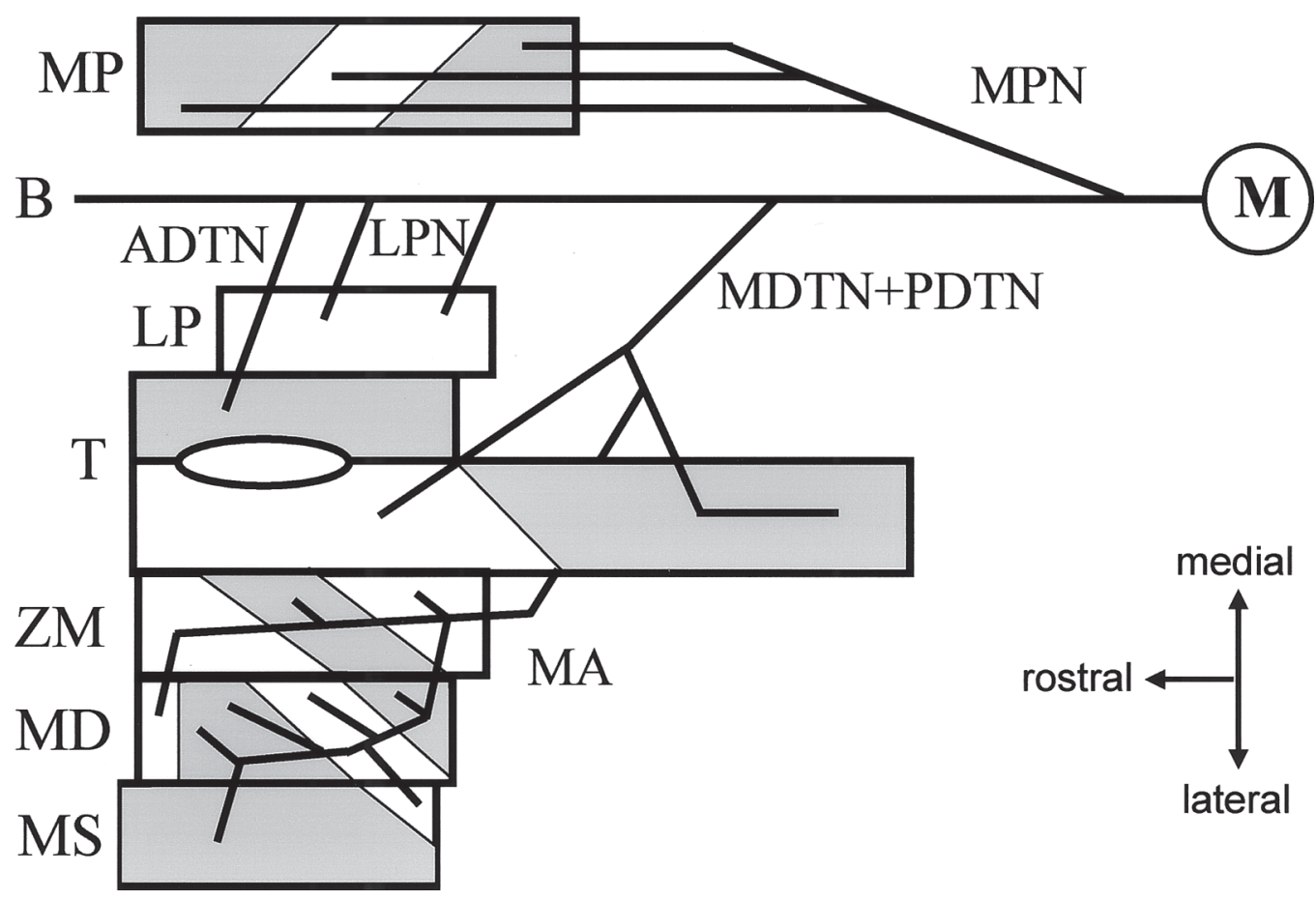

Fig. 6. Branch pattern of the P. cinereus mandibular nerve into the masticatory muscle and the Nerves layer in the mastication muscle depend on the distribution pattern. ADTN: Anterior deep temporal nerve; B: Buccal nerve; LP: Lateral pterygoid muscle; M: Mandibular nerve; MA: Masseteric nerve; MD: Masseter deep layer; MDTN: Medial deep temporal nerve; MP: Medial pterygoid muscle; MS: Masseter superficial layer; PDTN: Posterior deep temporal nerve; T: Temporalis muscle; ZM: Zygomaticomandibular muscle.

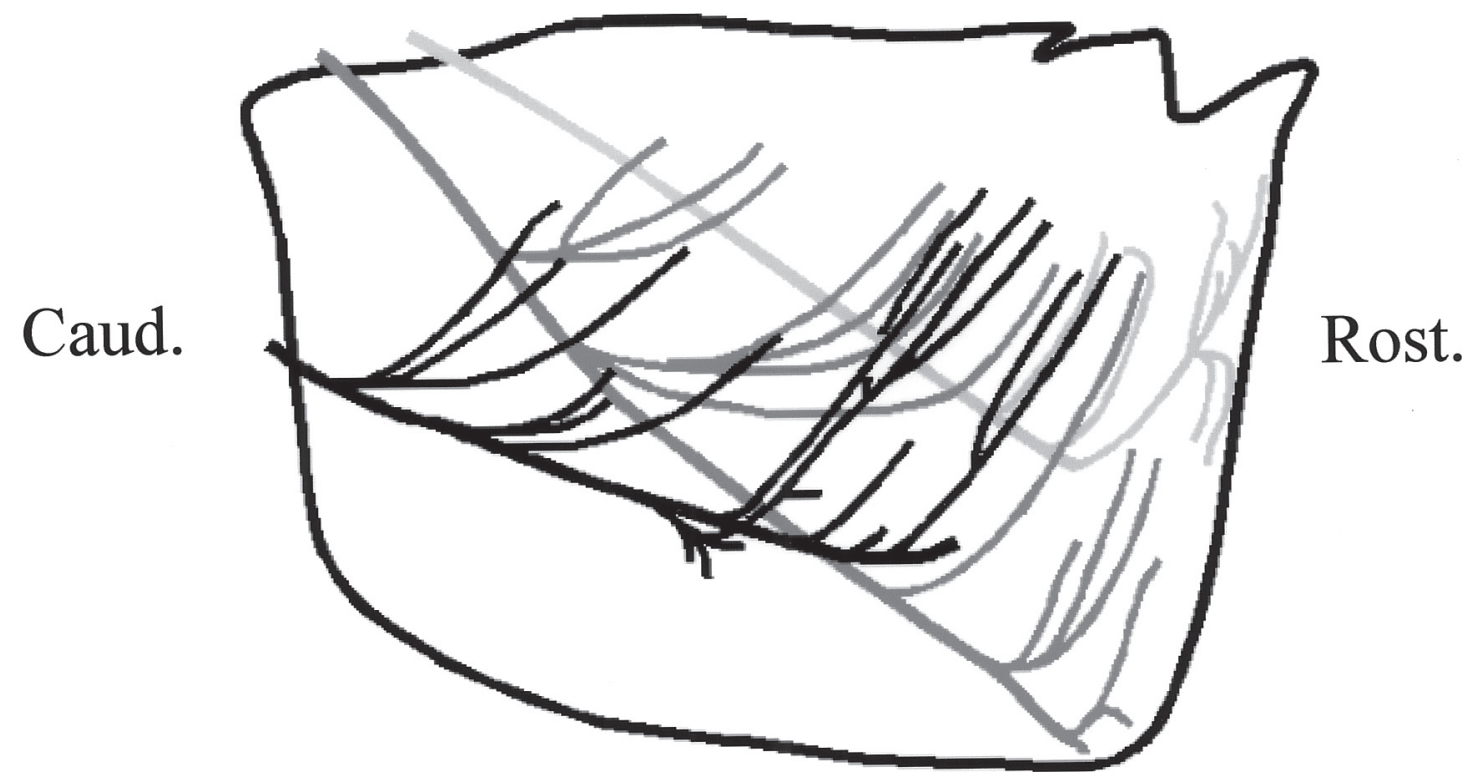

Fig. 7. Nerve distribution in the deep layer of the Medial Pterygoid muscle (Lateral view). 


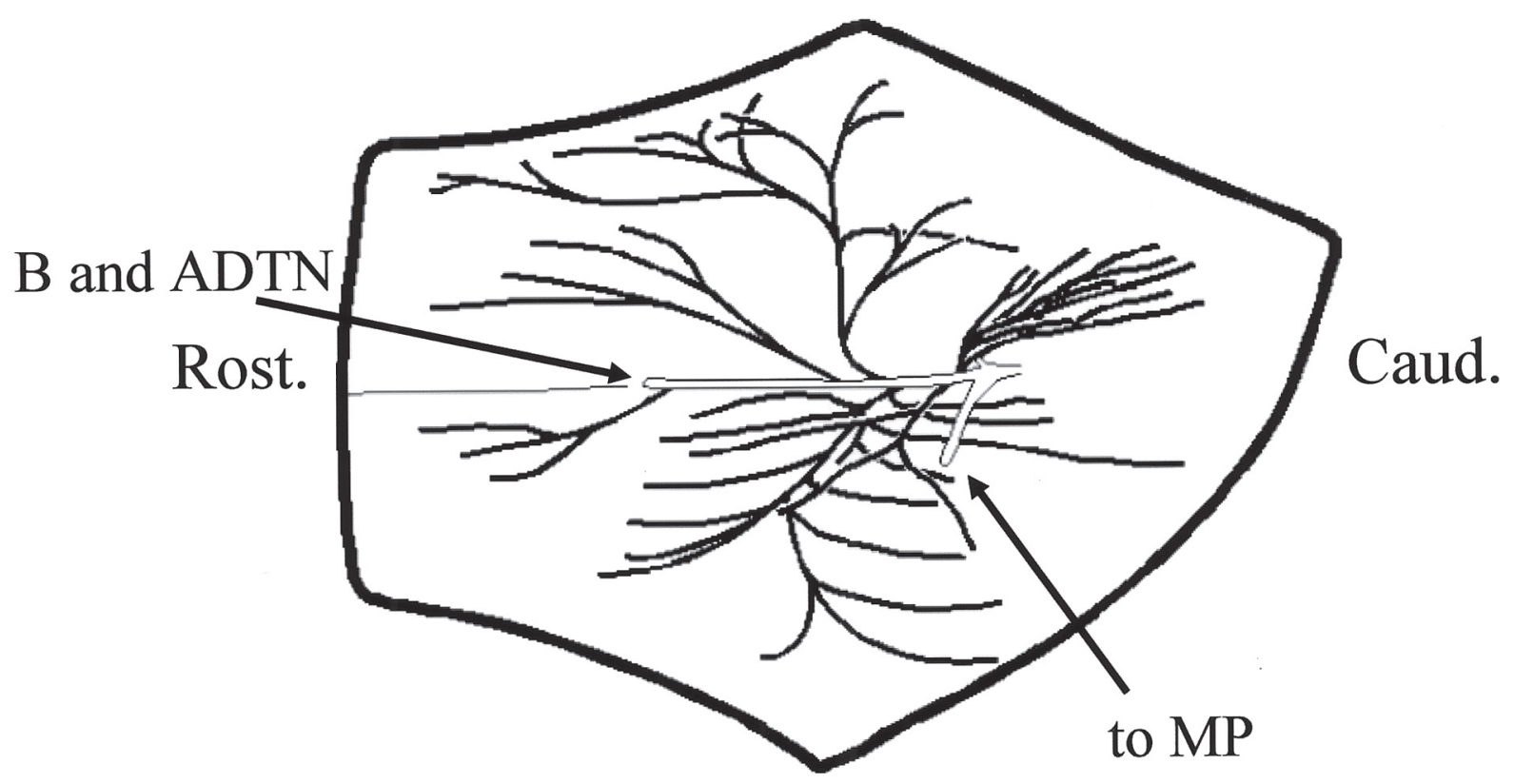

Fig. 8. Nerve distribution in the deep layer of the Lateral Pterygoid muscle (Medial view).

es before entering the muscle as internal, medial and lateral branches. No aponeurosis was observed in the medial pterygoid muscle. The internal branch innervated the rostro-internal area, the lateral branch (mandibular side) innervated the caudo-lateral area and the medial branch innervated the region between both. Therefore, the nerves in the medial pterygoid muscle were arranged in three layers from rostro-internal to caudo-lateral (Fig. 7).

\section{Lateral pterygoid nerve}

The lateral pterygoid nerve, anterior deep temporal nerve and buccal nerve were derived from a common trunk. The lateral pterygoid muscle had two heads that arose from the lateral aspect of the pterygoid plate and infratemporal fossa, and inserted into the anterior and medial aspect of mandibular condyle and temporo-mandibular joint disk. Some of the twigs branched off the common trunk as the muscle enlarged rostro-caudally. The distribution pattern of the nerves in the lateral pterygoid muscle appeared to be separate to the superior and inferior heads but it was not possible to discriminate them with certainty (Fig. 8).

\section{Deep temporal nerve}

The deep temporal nerve was divided into three nerves: anterior, medial and posterior deep temporal nerves respectively. The anterior deep temporal nerve passed into the temporalis muscle after ramification of the lateral pterygoid nerve, and it innervated the internal muscle bundle of the temporalis muscle at the coronoid process. The medial deep temporal nerve passed posterior to the coronoid process and innervated an area lateral to the coronoid process. The posterior deep temporal nerve passed into the posterior area of the temporalis muscle, and was distributed to the posterior area (Fig. 9).

\section{Zygomaticomandibular muscle}

The nerve that innervated the zygomaticomandibular muscle branched off the posterior deep temporal nerve. It was distributed to the lateral area of the coronoid process. This area could not be used to subdivide the temporalis muscle clearly because there was no aponeurosis. However, the nerve distribution pattern was quite different from that of the temporalis muscles. The muscle displayed three layers of nerves from rostro-medially to caudo-laterally. One of the twigs (c) passed into the anterior area of the deep masseter layer from the medial side, and innervated a small anterior area of the muscle (Fig. 10).

\section{Masseteric nerve}

The masseter muscle was divided into a superficial muscle layer and a deep muscle layer. The masseteric nerve passed into the posterior area of the deep muscle layer. It ran rostro-inferiorly and some twigs branched off to the deep layer. The caudal twigs innervated the post-internal area, the rostral twigs innervated the rostrolateral area and the middle twigs innervated the area between both areas. The nerve that penetrated the zygomaticomandibular muscle as described above innervated the most rostral area of the muscle. Therefore, four nerves innervated the masseter deep layer. The superficial 


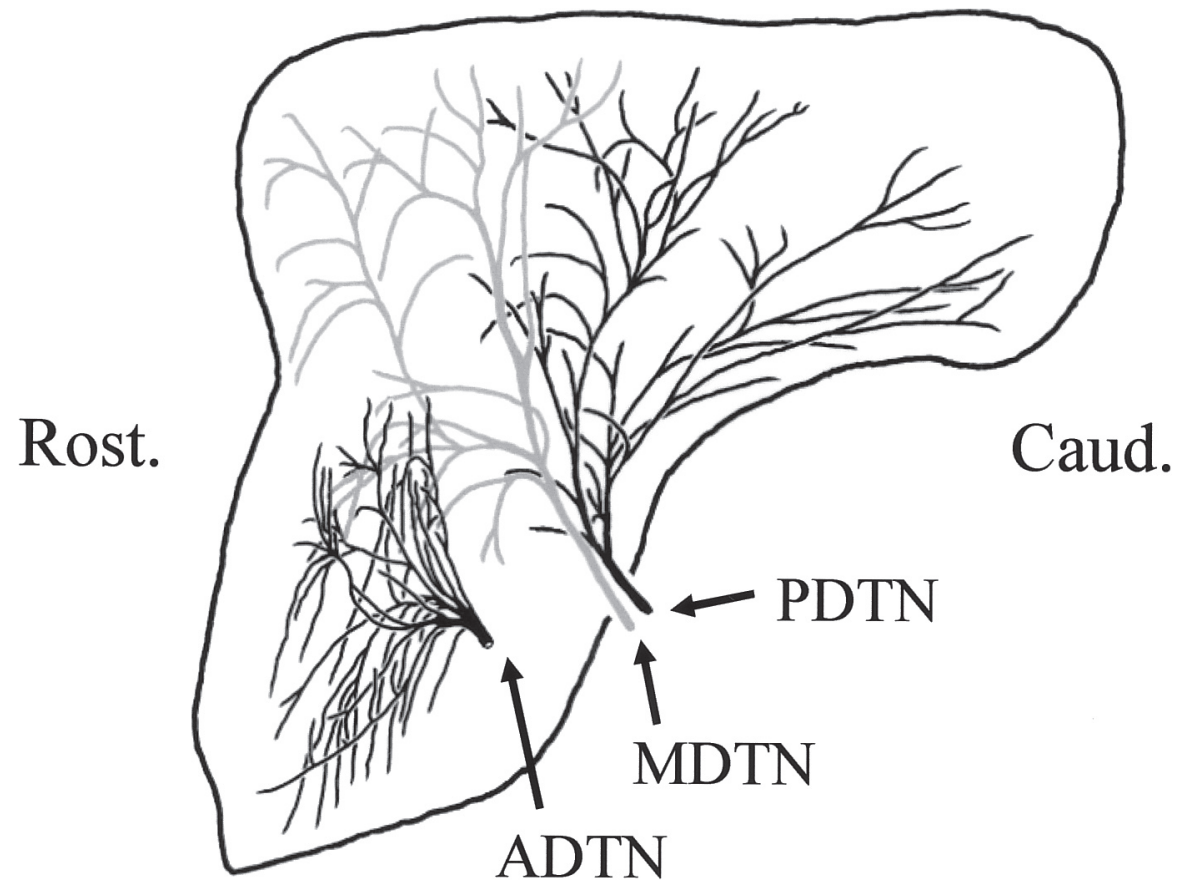

Fig. 9. Nerve distribution in the deep layer of the Temporalis muscle (Medial view).

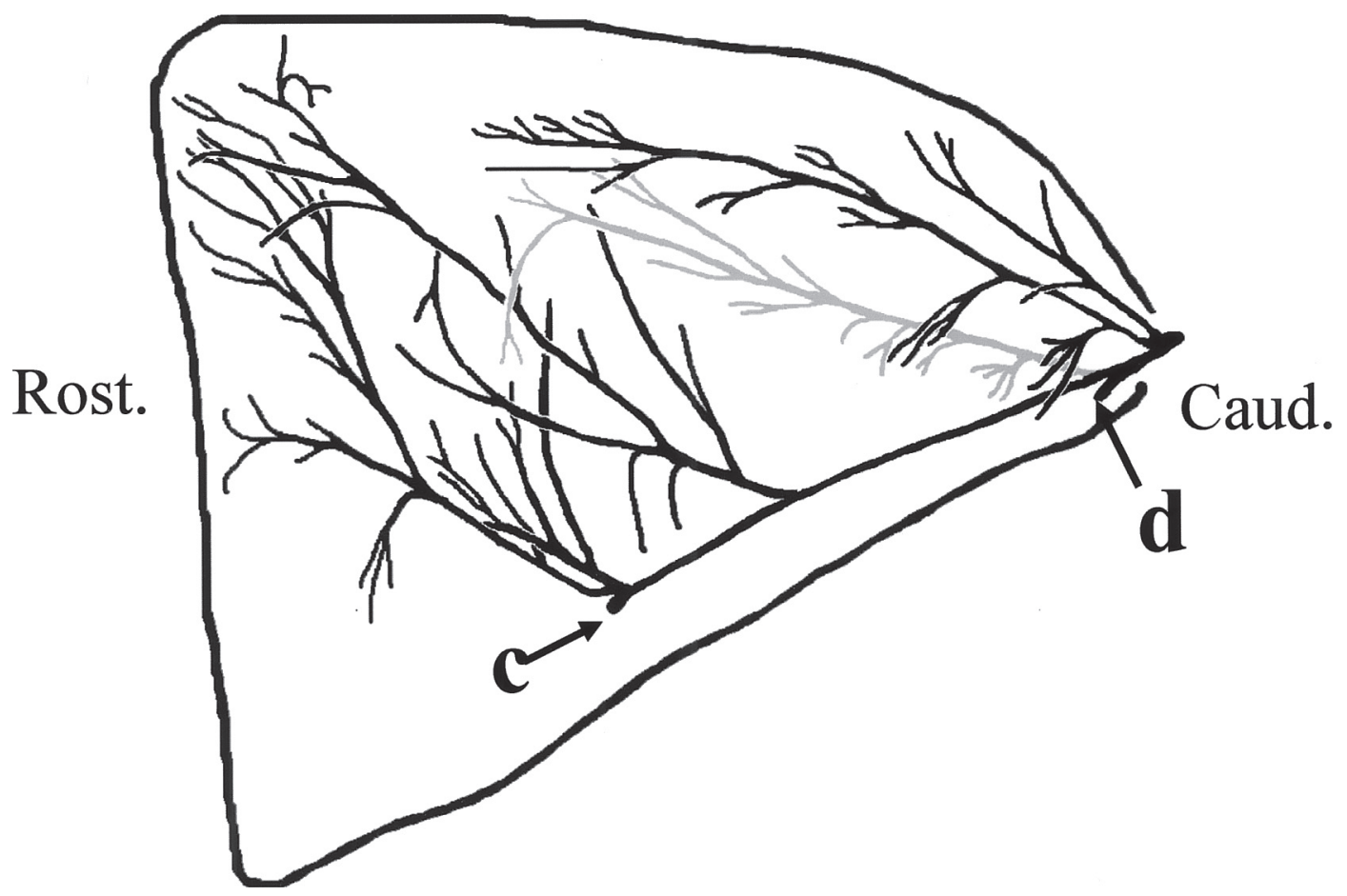

Fig. 10. Nerve distribution in the deep layer of the Zygomaticomandibular muscle (Medial view). Points $\mathrm{c}$ and d continue to the masseter deep layer. 


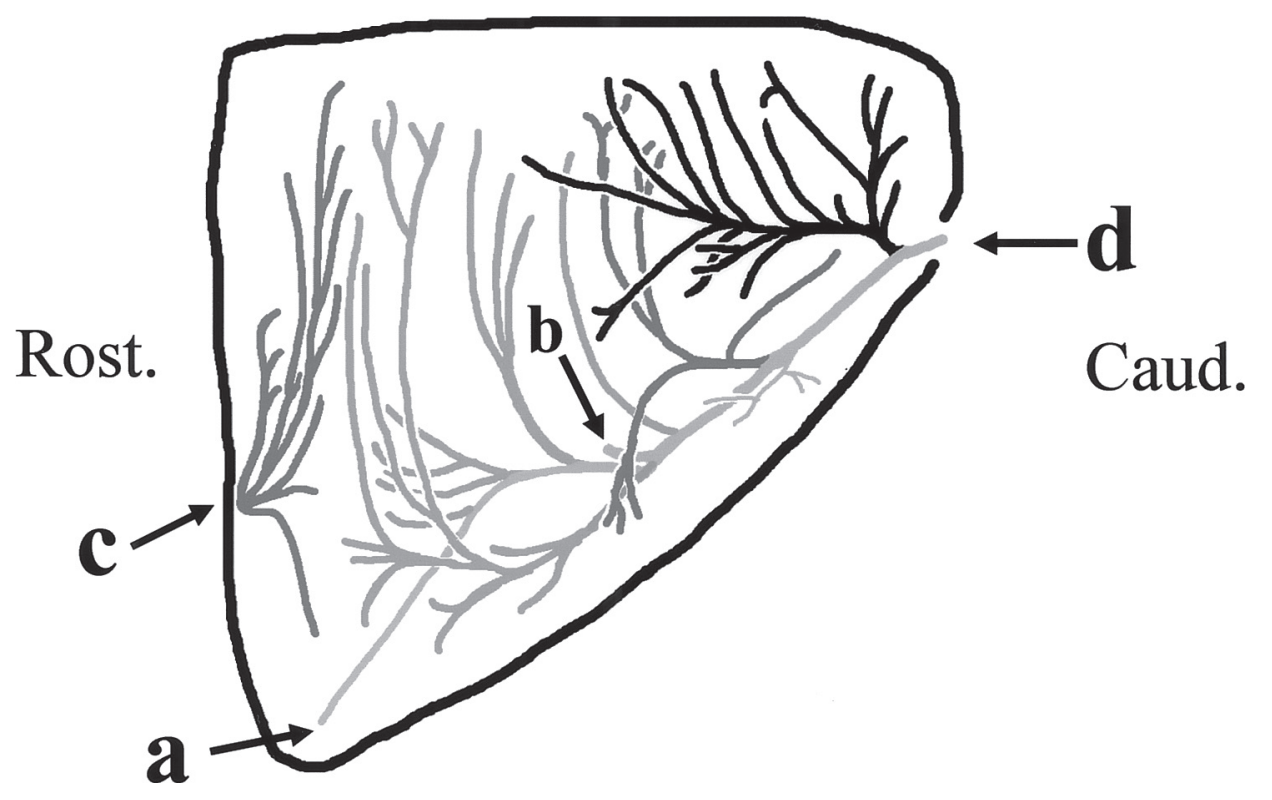

Fig. 11. Nerve distribution in the deep layer of the masseter (Medial view). Points $\mathrm{c}$ and $\mathrm{d}$ are continued from the zygomaticomandibular muscle. Points $\mathrm{a}$ and $\mathrm{b}$ continue to the masseter superficial layer.

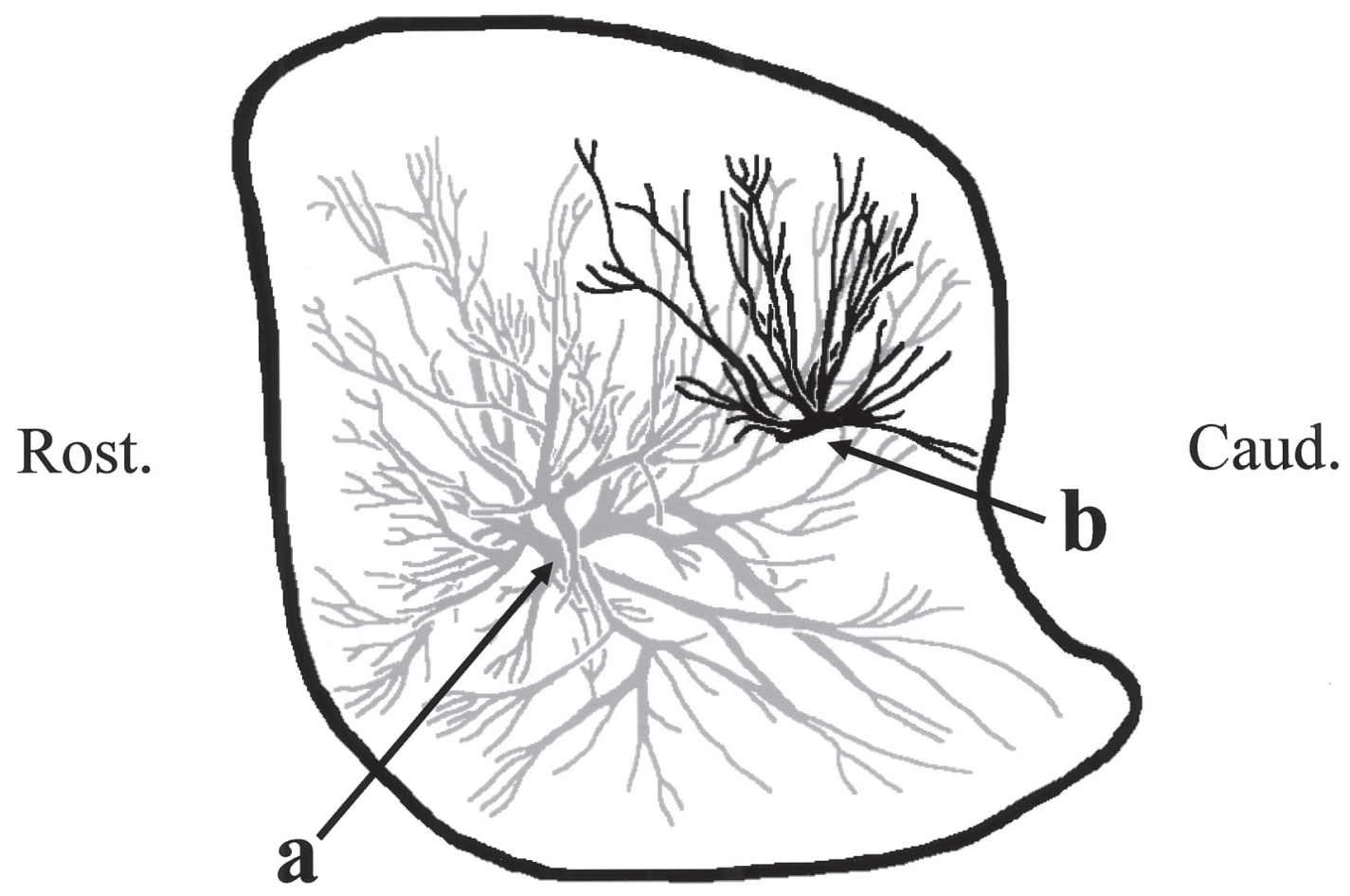

Fig. 12. Nerve distribution in the superficial layer of the masseter (Medial view). Points a and $b$ continue from the masseter deep layer. 
muscle layer was divided into two layers by the nerve. The terminal branch of the masseteric nerve innervated the rostro-lateral area of this muscle layer. A nerve that branched at the middle of the deep layer innervated the caudo-internal area of the superficial muscle layer. Therefore, the superficial muscle layer was divided into rostrolateral and caudo-internal nerve layers. The rostro-lateral nerve layer was more extensive than the caudo-internal nerve layer (Figs. 11, 12).

\section{Discussion}

The masticatory muscles comprise a mass that is composed of four main groups. The mass can be divided into two main components: the medial pterygoid muscle and the others. From a developmental perspective, the masseter, temporalis and lateral pterygoid muscles originate from the common lateral masticatory mass (Barghusen, 1968; Ellen et al., 1987; Merida Velasco et al., 1993; Reuter, 1993). The nerve that subsequently divides into the muscle. According to the distribution pattern of the masticatory muscles in the pig, Koppe et al. (1988) suggested that the paths of the nerves and the position of the aponeuroses were not related. Tomo et al. (1993), Nakajima et al. $(1998,2000)$ and Nakajima (2001) have classified the masticatory muscles in dog, kangaroo and humans according to their innervations and proposed that this provides a better insight into phylogenetic relationships and function. Davison et al. (1990) described the structure of the $P$. cinereus masticatory muscle but they did not recognize the lamination of the medial pterygoid muscle. They suggested that the masseter could be divided into superficial and deep layers. The superficial layer consisted of three parts and the deep layer consisted of two parts based on its tendons and origin. They provided no description of the zygomaticomandibular muscle. Blanksma et al described in their EMG study that the human masseter could be divided into three functional components (1992). They also claimed that the superficial portion of masseter could be divided into more than three regions. Other authors have described the relation between the internal anatomy of the masticatory muscles and their EMG activity (Herring et al., 1989; Mc Millan, 1991; Stalberg, 1987; Weijs, 1993).

The nerve layers of the masticatory muscles in the P. cinereus are shown in Fig. 6. In our study of the innervation patterns of the masticatory muscles, masseter was divided into two layers: a superficial muscle layer and a deep muscle layer. The superficial muscle layer was supplied by two nerve branches arranged a rostrolaterally and caudo-internally. The deep layer consisted of a small rostral portion and a main portion. The main portion comprised three nerve layers from rostro-lateral to caudo-internal. The medial pterygoid muscle consisted of three nerve layers from a rostro-internal to a caudo- lateral direction. That is to say, the nerve layers in the medial pterygoid muscle and the masseter were arranged in opposite directions. It seem to be possibility that these arrangements relate to the grinding functions of the muscles. When the jaws produce a grinding movement, the masseter on one side and the medial pterygoid muscle on the other act together as co-operative muscles. When jaw movement produces an incisive bite, all the masseter and medial pterygoid muscles act together as a co-operative unit. But we can not say for certain whether the estimation is collect or not because of no performs of functional analysis. In previous studies of the lamination of the masseter deep layer in humans, dogs and kangaroo, no one has observed oblique structures (Tomo et al., 1993; Nakajima et al., 1998, 2000). Only the deep nerve layer of the $P$. cinereus's masseter displays four oblique laminae. This characteristic may indicates that the lamination of the $P$. cinereus masseter deep layer has been adapted to grinding movements. Davison et al. (1990) has calculated that the $P$. cinereus's masseter occupies approximately $48.1 \%$ by weight of the total masticatory muscle weight, with medial pterygoid contributing only $5.2 \%$. Thus, we propose that the masseter is adapted for grinding mainly whereas the medial pterygoid muscle assists mainly in stabilizing this action. The temporalis muscle was innervated by three deep temporal nerves: anterior, medial and posterior. The $P$. cinereus's temporalis muscle formed a fan shape and was elongated in the caudo-rostral direction. The shape is typical herbivorous animal. The muscle fibers originated from the temporal fossa and the insertion surrounded the coronoid process. The muscle masses of the anterior and medial areas were thick. It is estimated that the anterior and medial masses of the muscle in $P$. cinereus are used for biting and the posterior muscle mass for retreating the mandible. The anterior deep temporal nerve innervated the internal area of the coronoid process. The area innervated by the medial deep temporal nerve was the thickest part of the temporalis muscle. We propose that this area is involved mainly in biting. The area innervated by the posterior deep temporal nerve was the widest and thinnest part of the temporal muscle and we propose that it retreat the mandible. In $P$. cinereus, the masseter, zygomaticomandibular and temporalis muscles appear to connect more tightly than other mammals that I have been observed. The zygomaticomandibular muscle looks like the rostro-lateral area of the temporalis muscle. Nevertheless, it should be thought of as separate from the temporalis because its controlling nerve branched off the posterior deep temporal nerve. One of the twigs from the nerve entered the anterior small portion of the deep layer of the masseter. This indicates that the zygomaticomandibular muscle has a close relationship with the deep layer of masseter. 


\section{Acknowledgements}

We thank especially Dr. Catherine M. Kemper, curator of mammals (South Australian Museum).

\section{References}

1) Akita $K$, Shimokawa $T$ and Sato $T$. Positional relationship between the masticatory muscle and their innervating nerves with special reference to the lateral pterygoid and the midmedial and discotemporal muscle bundle of temporalis. J Anat 2000; 197:291 -302 .

2) Barghusen HR. The lower jaw of cynodonts (Reptilia, Therapsida) and the evolutionary origin of mammal-like adductor jaw musculature. Postilla 1968; 116:1-49.

3) Blanksma NG, Van Eijden TMJ and Weijs WA. Electromyographic heterogeneity in thehuman masseter muscle. J Dent Res 1992; 71:47-52.

4) Davison CV and Young WG. The Muscles of Mastication of Phascolarctos cinereous (Phascolarctidae: Marsupialia). Aust J Zool 1990; 38:227-240.

5) Deguchi T, Takemura A and Suwa F. The lamination of the common opossum masseter (didelphis marsupialis). Okajima Folia Anat Jpn 2001; 77:233-242.

6) Ellen JL, Alphonese RB and Henry JJ. Critical periods in the prenatal morphogenesis of the human lateral pterygoid muscle, the mandibular condyle, the articular disk, and medial articular capsule. Am J Orthod Dentofac Orthop 1987; 91:22-28.

7) Grant PG. Lateral pterygoid: Two muscles. Am J Anat 1973; 138: $1-10$.

8) Herring SW. Functional design of cranial muscles: Comparatative and physiological studies in pigs. Amer Zool 1980; 20:283-293.

9) Koppe T, Schumacher B and Schumacher K. Funktionelle. Morphologie des maxillo-mandibularen Apparatus beim Miniaturschwein MINI-LEWE. 8. Besprechung der Ergebnisse uber die Entwicklung des intramuskularen Nervenverzweigungsmusters in den Kaumuskeln. Anat Anz 1988; 166:97-104 (in German).

10) Lau H, Schumacher GH, Shultz M, FanghAne J and Himstedt HW. A. Menning. Zur Topographie der muskularen Nervenausbreitungen 8. Kaumuskeln. M. temporalis verschiedener Kautypenvertreter. Anat Anz Bd 1974; 135S:481-490 (in German).

11) McMillan AS and Hannam AG. Motor-unit territory in the human masseter muscle. Archs Oral Biol 1991; 36:435-441.

12) Nakajima $K$, Tomo $S$, Oka $K$, Wakatuki E and Ide Y. Examination of nerve distribution to masticatory muscles using a silicon permeation technique. Okajima Folia Anat Jpn 1998; 75:225-230.

13) Nakajima k, Townsend G, Tomo S, Ide Y, Oka K and Wakatuki E. Lamination of the Masticatory muscles in the kangaroo according to their innervation. Okajima Folia Anat Jpn 2000; 76:303-310.

14) Nakajima K. Nerves distribution in the masticatory muscles using a human silicon permeation method. Caused and Effect of Human Variation. Australasian Society for Human Biology, Univ of Adelaide 2001; pp. 46-60.

15) Reuter K. Uber die Entwickelundder Kaumuskulatur bein Schwein. Anat Hefte 1987; 7:239-261.

16) Sawada T. Anatomical and morphological studies of human masticatory muscle-The laminar structure of the masseter muscle and the temporal muscle. Med J Kobe Univ 1976; 25:251-279 (in
Japanese),

17) Schumacher GH, Lau H, Menning A, Schltz M, Himstedt HW and Fanghanel J. Zur Topographie der muskularen Nervenausbreitungen 7. Kaumuskeln. M.masseter varschiedenor Kautypenvertreter. Anat Anz Bd. 1974; 135s:470-480 (in German).

18) Shankland WE, Negulesco JA and Blaize O'Brian BS. The "PreAnterior Belly" of the Temporalis muscle: A preliminary study of a newly described muscle. J Prosthetic Dent 1996; 14:106-113.

19) Shimokawa $T$, Akita $K$, Soma $K$ and Sato $T$. Innervation an analysis of the small muscle bundles attached to the temporalis: truly new muscles or merely derivatives of the temporalis. Surg Radiol Anat 1998; 20:329-334.

20) Shimokawa T, Akita K, Soma $K$ and Sato T. An anatomical study of the muscles Innervated the masseteric nerve. Okajimas Folia Anat Jpn 1999; 75:271-280.

21) Sicher H. Oral Anatomy $2^{\text {nd }}$ ed., St. Louis C.V.Mosby Co. 1952; pp. $130-137$.

22) Stalberg E and Eriksson P. A Scanning Electromyographic Study of the Topography of Human Masseter Single Motor Units. Archs oral Biol 1987; 32:793-797.

23) Toldo C. Der Winkelfortsatz des Unterkiefers beim Menschen und bei den Saugetieren und die Beziehungen der Kaumuskeln zu demselben. Tail 2. Sitzungsberichte der K. Akademie zu Wien, Mathem. Naturwiss 1905; 114:315-387 (in German).

24) Tomo S. Morphological classification of the mastication muscle based on there innervation. Ochanomizu Medical Journal, Tokyo 1990; 38:59-71 ( in Japanese).

25) Tomo S, Hirakawa T, Nakajima K, Tomo I and Kobayashii S. Morphological classification of the masticatory muscles in dogs based on their innervation. Ann Anat 1993; 175:373-380.

26) Velasco JRM, Vazquez JFR and Collado JJ. The relationships between the temporomandibular joint disc and related masticatory muscles in humans. J Oral Maxillofac Surg 1993; 51:390-395.

27) Watanabe Y. Morphology and innervation of the masticatory muscles in sheep. J. Kyushu Dental Society 1997; 51:265-270.

28) Weijs W, Juch P, Kwa S and Korfage J. Motor Unit Territories and Fiber Types in Rabbit Masseter Muscle. J Dent Res 1993; 72:1491-1498.

29) Widmer CG, Klugman D and English AW. Anatomical Partitioning and Nerve Branching Patterns in the Adult Rabbit Masseter. Acta Anat 1997; 159:222-232.

30) Yoshikawa T. The comparative anatomical study of M. maxillomandibularis and M. zygomaticomandibularis. Acta Anato Nippon $1969 ;$ 44:72-74 (in Japanese).

31) Yoshikawa $T$ and Suzuki T. The Lamination of the human masseter -The new identification of M. temporalis superficialis, M. maxillo-mandibularis and $\mathrm{M}$. zygomatico-mandibularis in the human anatomy. Acta Anat Nippon 1962a; 37:260-267 (in Japanese).

32) Yoshikawa $T$ and Suzuki $T$. The Lamination of the masseter of the bat: Act Anat Nippon 1962b; 37:352-358 (in Japanese).

33) Yoshikawa T, Suzuki T, Kiuchi R and Matsuura H. The Comparative anatomy of the Muscles masseter of the mammals. Acta Anat Nippon 1961; 36:53-71 (in Japanese).

34) Yoshikawa, T, Suzuki T, Kiuche R and Matsuura H. The Lamination of the M. masseter of the crab-eating monkey, orang-utan and gorilla. Acta Anat Nippon 1962a; 37:206-217 (in Japanese).

35) Yoshikawa $T$, Suzuki $T$, Kiuchi R and Matsuura $H$. The lamination of the masseter of the ruminantia. Acta Anato Nippon 1962b; 37:430-442 (in Japanese). 